\title{
Pioglitazone: How Pharmacology Can be used Interchangeably with Mammonology in the Developing Countries?
}

\section{Mina T Kelleni*}

Department of Pharmacology, Faculty of Medicine, Minia University, Egypt

\begin{abstract}
Exporting Pioglitazone either as an active ingredient or as already made trade named packages to the developing countries where many conditions favor carcinogenicity and medical illiteracy of its relationship with urinary bladder carcinoma is so prevalent not only among patients but also among a proportionate sector of health care providers, is nearly the perfect crime of the new millennium.
\end{abstract}

Keywords: Pioglitazone; FDA; Bladder cancer

Abbreviations: FDA: Food and Drug Administration (USA); PROactive Study: PROspective PioglitAzone Clinical Trial in MacroVascular Events study

\section{Introduction}

In the first chapter named "what is pharmacology?" of the well know "Rang and Dale's Pharmacology" text book, one of the authors wrote a phrase that needs to be highlighted in the beginning of this article; he said describing the current pharmacology and pharmaceutical industry: "No other biomedical "ology" is so close to Mammon", and I totally agree with him [1].

\section{Once Upon an Evil Time}

\section{The beginning of the tragedy}

Even before its advent in 1999; Pioglitazone as well as other members of the thiazolidinediones group have been questioned for a relationship with colon carcinoma in mice; an adverse effect that was subsequently evidenced to occur also in some types of human colon cancer cells $[2,3]$. Similarly, preclinical studies have also showed that bladder tumors were observed in male rats receiving doses of pioglitazone that produced blood drug levels equivalent to those resulting from a clinical dose [4].

\section{The FDA officials must be questioned and policy changed}

Only in 2005 some scientists noticed a possible relationship between pioglitazone and bladder neoplasm in humans as they noted more cases ( 14 vs $6 ; \mathrm{P}=0.069$ ) of bladder neoplasm in the pioglitazone versus placebo arms in the famous PROactive study [5].

These results, I claim, were not properly managed with the expected care and thorough analysis by the U.S. Food and Drug Administration (FDA) and it's not the first time as we may recall the infamous delay in banning troglitazone in USA for more than 2 years after its withdrawal in UK, though since its advent a remarkable higher incidence of fulminant liver hepatitis has been clearly noted and described; this may also remind us of the reluctant FDA handling of the early cardiovascular adverse effects of both rosiglitazone and pioglitazone [6].

This has remained the FDA way dealing with pioglitazone increased risk of urinary bladder carcinogenicity till September 2010 when the evidence became more and more disturbing, so that at last an announcing was issued from the FDA that "the agency is reviewing data from an ongoing, ten-year epidemiological study designed to evaluate whether Actos, or pioglitazone, is associated with an increased risk of bladder cancer. Findings from studies in animals and humans suggest this is a potential safety risk that needs further study" to be followed in July 2011 by a similar alert from the European Medicines Agency! [4,7].

\section{Countries that didn't accept to share in the crime}

In June 2011, France National Agency for the Safety of Medicine and Health Products banned pioglitazone relying on the results appearing from large cohort and case control studies; some suggesting a bladder cancer association risk with a duration of intake of more than one to two years, while others conclude that the association with bladder cancer disrespects the treatment duration; also a French retrospective cohort study of 1491060 patients has found a significant increased risk of bladder cancer in pioglitazone users [8,9]. Germany has also followed the footsteps of France in the same month and year to be followed by Tunisia and Muritius [10].

\section{The victims}

A very small minority of health care providers in the developing countries has been, and unfortunately even still are, aware of these results; hundreds of millions of patients all over these poor countries, where many conditions favor carcinogenicity; polluted air, water, food, smoking ... etc. were, and are, totally ignorant about it and thus have been denied their ethical and medico-legal right to choose a possibly safer drug. In my country, Egypt, pharmaceutical companies promoting pioglitazone didn't even put the dark box label regarding its potential urinary bladder carcinogenicity till the moment writing this article and they may even simply and truly reply that no local authority has asked them to do!

\section{Crime Revealed But Shame Delays The Confession}

Worldwide meta-analysis studies covering millions of people

After 2011 more and more evidence has continued to be built up. Canadian authors after reviewing and performing some meta-analysis

*Corresponding author: Mina T Kelleni, Assistant Lecturer of Pharmacology, Faculty of Medicine, Minia University, Egypt, Tel: +201200382422; E-mail drthabetpharm@yahoo.com

Received June 27, 2014; Accepted August 07, 2014; Published August 16, 2014

Citation: Kelleni MT (2014) Pioglitazone: How Pharmacology Can be used Interchangeably with Mammonology in the Developing Countries? J Diabetes Metab 5: 411 doi:10.4172/2155-6156.1000411

Copyright: @ 2014 Kelleni MT. This is an open-access article distributed under the terms of the Creative Commons Attribution License, which permits unrestricted use, distribution, and reproduction in any medium, provided the original author and source are credited. 
studies wrote a conclusion that exposure to pioglitazone is associated with an increased risk of bladder cancer and they've also stressed the inference of causality between the larger cumulative doses and longer duration of pioglitazone use and the greater risks of bladder cancer [11]. Furthermore, in 2012, an author writing in another well-known pharmacology textbook stated frankly: "the risk of bladder cancer appears to be cumulatively increased with high doses", the author added that because of toxicities the FDA restrict rosiglitazone to small populations including some who "don't wish to be on pioglitazone or a pioglitazone containing drug"! [12].

In another meta-analysis that involved five studies included 2350 908 diabetic patients, pioglitazone was found to be associated with a significantly higher risk of bladder cancer (relative risk [RR] 1.17, 95\% Confidence Interval (CI) 1.03-1.32, $\mathrm{P}=0.013$ ) [13]. Furthermore, in 2013, six studies involving 215142 patients using pioglitazone, with a median period of follow-up of 44 months revealed that the hazard of developing bladder cancer was significantly higher in patients using pioglitazone (hazard ratio 1.23; 95\% CI 1.09-1.39; $\mathrm{I}^{2}=0 \%$ ) compared with control groups [14]. Still other authors have also showed that a relatively short duration of pioglitazone treatment was associated with the occurrence of bladder cancer [15].

\section{Mammon sends the FDA his deepest gratitude}

Mammon, I think, couldn't do better; the drug nowadays heavily restricted in the developed countries is exported and heavily prescribed in the developing countries where a lot is being offered by the pharmaceutical industry to tempt the ignorant as well as the heartless prescribers. Furthermore, even the simple fact that early stoppage of pioglitazone is highly likely to save lives is being unknown or hidden in these countries; Zhu et al. [13] showed that there's no relation between pioglitazone and bladder cancer was found for duration of therapy $<12$ months and cumulative dose $<28.000 \mathrm{mg}$. The relative risk for bladder cancer in subjects with 12-24 months of pioglitazone use was 1.34 (95\% CI 1.08-1.66, $\mathrm{P}=0.008)$. The effect was even stronger for cumulative treatment duration $>24$ months $(\mathrm{RR} 1.38,95 \% \mathrm{CI} 1.12-1.70, \mathrm{P}=0.003)$ [13].

Hilariously, in the official FDA website you may read: "at this time, FDA has not concluded that Actos increases the risk of bladder cancer" just below the phrase: "an increased risk of bladder cancer was observed among patients with the longest exposure to Actos, as well as in those exposed to the highest cumulative dose of Actos"! You may also read in the same page what the FDA is relying on: "The drug manufacturer, Takeda, has conducted a planned analysis of the study data at the fiveyear mark, and submitted their results to FDA"! [4].

\section{Risk benefit ratio}

Moreover, If we remind that pioglitazone treatment is not only associated with increased risk of urinary bladder carcinogenicity but also is associated with an increased risk of fractures in both men and women; that fracture risk is increased even in younger women and that pioglitazone is also associated with a higher incidence of hospitalization for heart failure then one may wonder if any claimed benefit may overcome these risks $[16,17]$. You may also consider supporting my urgent request demanding that this drug should not be exported to our poor developing countries.

\section{Conclusion - To Remain Silent Means You Share in the Crime}

In my opinion as a physician, pharmacologist and first as a human being; the FDA waiting for more results regarding pioglitazone urinary bladder carcinogenicity is not appropriate at all, this should be disregarded and we shouldn't remain silent towards the enormous evidence that has been already revealed; we should work hard and fast to ban pioglitazone further entrance to the developing countries. I believe this what the founding fathers of USA would do if they were among us today.

The author declares that there's no conflict of interest of any sort with anyone who may be offended by this article.

\section{References}

1. Rang HP, Dale MM, Ritter JM, Flower RJ (2012) Henderson G Rang and Dale's Pharmacology, Seventh international edition, Elsevier Churchill Livingstone publication 1: 2 .

2. Lefebvre AM, Chen I, Desreumaux P, Najib J, Fruchart JC, et al. (1998) Activation of the peroxisome proliferator-activated receptor gamma promotes the development of colon tumors in C57BL/6J-APCMin/+ mice. Nat Med 4 1053-1057.

3. Choi IK, Kim YH, Kim JS, Seo JH (2008) PPAR-gamma ligand promotes the growth of APC-mutated HT-29 human colon cancer cells in vitro and in vivo. Invest New Drugs 26: 283-288.

4. Food and Drug Administration. FDA Drug Safety Communication: Update to ongoing safety review of Actos (pioglitazone) and increased risk of bladder cancer. Rockville: FDA, 2011

5. Dormandy JA, Charbonnel B, Eckland DJ, Erdmann E, Massi-Benedetti M et al. (2005) Secondary prevention of macrovascular events in patients with type 2 diabetes in the PROactive Study (PROspective pioglitAzone Clinical Trial In macroVascular Events): a randomised controlled trial. Lancet 366:1279-1289.

6. Sinha B, Ghosal S (2013) Pioglitazone--do we really need it to manage type 2 diabetes? Diabetes Metab Syndr 7: 52-55

7. European Medicines Agency. Press Release: European Medicines Agency recommends new contra-indications and warnings for pioglitazone to reduce small increased risk of bladder cancer. London: EMA, 2011.

8. Piccinni C, Motola D, Marchesini G, Poluzzi E (2011) Assessing the association of pioglitazone use and bladder cancer through drug adverse event reporting Diabetes Care 34: 1369-1371.

9. Neumann A, Weill A, Ricordeau P, Fagot JP, Alla F, et al. (2012) Pioglitazone and risk of bladder cancer among diabetic patients in France: a populationbased cohort study. Diabetologia 55: 1953-1962.

10. Tseng C-H (2012) Pioglitazone and bladder cancer in human studies: Is it diabetes itself, diabetes drugs, flawed analyses or different ethnicities? Journal of the Formosan Medical Association 111: 123-131.

11. Johnson JA, Colmers IN (2012) Balancing the risks and benefits for pioglitazone in type 2 diabetes. Diabetes Res Clin Pract 98: 1-2.

12. Martha Kennedy SN (2012) Pancreatic hormones and antidiabetic drugs chapter in Bertram G. Katzung, Susan B. Masters and Anthony J. trevor's Basic and Clinical Pharmacology textbook, (12 $2^{\text {th }}$ Edn) McGraw Hill medical publication 41: 758 .

13. Zhu Z, Shen Z, Lu Y, Zhong S, Xu C (2012) Increased risk of bladder cancer with pioglitazone therapy in patients with diabetes: a meta-analysis. Diabetes Res Clin Pract 98: 159-163.

14. Ferwana M, Firwana B, Hasan R, Al-Mallah MH, Kim S, et al. (2013) Pioglitazone and risk of bladder cancer: a meta-analysis of controlled studies. Diabet Med 30: 1026-1032.

15. Fujimoto K, Hamamoto Y, Honjo S, Kawasaki Y, Mori K, et al. (2013) Possible link of pioglitazone with bladder cancer in Japanese patients with type 2 diabetes. Diabetes Res Clin Pract 99: e21-23.

16. Aubert RE, Herrera V, Chen W, Haffner SM, Pendergrass M (2010) Rosiglitazone and pioglitazone increase fracture risk in women and men with type 2 diabetes. Diabetes Obes Metab 12: 716-721.

17. Giles TD, Miller AB, Elkayam U, Bhattacharya M, Perez A (2008) Pioglitazone and heart failure: results from a controlled study in patients with type 2 diabetes mellitus and systolic dysfunction. J Card Fail 14: 445-452. 